Jurnal Health Sains: p-ISSN: 2723-4339 e-ISSN: 2548-1398

Vol. 2, No. 8, Agustus 2021

\title{
ANALISA KEBUTUHAN TENAGA REKAM MEDIS BERDASARKAN BEBAN KERJA DENGAN METODE ABK-KES DI BAGIAN CASE MIX RUMAH SAKIT $X$ PALEMBANG TAHUN 2021
}

\author{
Hadi Priatmoko, Yuyun Yunengsih, Sali Setiatin \\ Politeknik Piksi Ganesha Bandung Jawa Barat, Indonesia \\ Email: hadi0704@gmail.com, yoen1903@gmail.com, salisetiatin@gmail.com
}

\begin{abstract}
INFO ARTIKEL ABSTRAK
Diterima

5 Agustus 2021

Direvisi

15 Agustus 2021

Disetujui

25 Agustus 2021

Kata Kunci:

ABK Kes; beban

kerja, petugas coder;

PMIK sumber daya

manusia

ABSTRAK yang tersedia harus diimbangi dengan beban kerja yang akan dijalankan, agar tercapai keselarasan dalam suatu pekerjaan. Sebagai proses mendapatkan jumlah jam kerja dalam menyelesaikan beban kerja dalam waktu tertentu dibutuhkan suatu analisis beban kerja. Penelitian ini dilakukan untuk menghitung jumlah kebutuhan tenaga PMIK yang dibutuhkan di Rumah Sakit X Palembang sesuai beban kerja dengan menggunakan metode Analisa Beban Kerja Kesehatan. Jenis penelitian ini jenis deskriptif menggunakan pendekatan kualitatif. Pengumpulan data menggunakan observasi dan wawancara terhadap PMIK Coder di Rumah Sakit X Palembang. Kualifikasi pendidikan PMIK Coder di Rumah Sakit X Palembang yaitu 4 (empat) PMIK D3 Rekam Medis. Perhitungan kebutuhan PMIK di Bagian SIK (Case Mix) menggunakan metode Analisis Beban Kerja Kesehatan (ABK-Kes) petugas sebanyak 4 (empat) PMIK dan di Rumah Sakit X Palembang sudah terdapat 4 (empat) PMIK sehingga jumlah petugas tersebut masih relatif aman untuk menyelesaikan tugas sesuai beban kerja yang ada. Kesimpulan dari penelitian ini yaitu jumlah PMIK coder di Rumah Sakit X Palembang terdapat 4 (empat) PMIK coder. Perhitungan kebutuhan SDMK di bagian SIK (Case Mix) menggunakan metode Analisis Beban Kerja Kesehatan (ABK-Kes) sebanyak 4 (empat) PMIK dan di Rumah Sakit X Palembang terdapat 4 (empat) PMIK sehingga jumlah petugas tersebut masih relatif aman untuk menyelesaikan tugas sesuai beban kerja yang ada.
\end{abstract}

ABSTRACT
The role of coders is important for hospitals. The available coders to
achieve harmony in a job. As a process to get the number of hours of
work needed to complete the workload in a certain time an analysis of
the workload is needed.This study was conducted to calculate the
number of PMIK personnel needed at Hospital X Palembang according
to workload analysis. This was a descriptive study with qualitative
approach. Data collection is using observation and interview to the
Coder employee at X Hospital Palembang.The education qualification of
Coder employees at X Hospital Palembang are 4 (four) PMIK with
Associate's Degree of Medical Records. Human Resources SDM of
SIK's calculation (Case Mix) uses the medical workload analysis (ABK-
Kes) method are 4 (four) PMIK and at X Hospital Palembang there are
4 (four) PMIK, so that the amount is still relatively safe to complete
Priatmoko, H., Yunengsih, Y., \& Setiatin, S. (2021) Analisa Kebutuhan Tenaga Rekam Medis
Berdasarkan Beban Kerja dengan Metode ABK-Kes di Bagian Case Mix Rumah Sakit X Palembang
Tahun 2021. Jurnal Health Sains 2(8). https://doi.org/10.46799/jhs.v2i8.249
2723-6927
Ridwan Institute


Analisa Kebutuhan Tenaga Rekam Medis Berdasarkan Beban Kerja dengan Metode ABK-Kes di Bagian Case Mix Rumah Sakit X Palembang Tahun 2021

Keywords:

medical workload

analysis;

workloadcoder

employees; PMIK

human resources tasks according to the existing workload. The conclusion of this study is the number of PMIK coders in Hospital X Palembang there are 4 (four) PMIK coders. Calculation of HRK needs in the SIK (Case Mix) section using the Health Workload Analysis (ABK-Kes) method of 4 (four) $P M I K$ and in X Palembang Hospital there are 4 (four) PMIK so that the number of officers is still relatively safe to complete tasks according to existing workloads.

\section{Pendahuluan}

Rumah sakit adalah institusi pelayanan kesehatan yang menyelenggarakan pelayanan kesehatan perorangan secara paripurna yang menyediakan pelayanan rawat inap, rawat jalan dan gawat darurat (Undang-Undang RI Nomor 44 tahun 2009 pasal 1).

Rekam Medis adalah berkas yang berisi catatan dan dokumen tentang identitas pasien, pemeriksaan, pengobatan, tindakan dan pelayanan lain yang telah diberikan kepada pasien (Azzahra \& Mufidi, 2021).

Rekam medis elektronik (RME) adalah versi digital dari rekam medis konvensional (berupa kertas) yang biasa digunakan di fasilitas kesehatan. RME berisi catatan dan informasi yang dikumpulkan oleh dan untuk dokter di fasilitas layanan kesehatan tersebut, yang digunakan untuk tujuan diagnosis dan perawatan kesehatan pasien (Gunawan \& Christianto, 2020). RME memungkinkan penyedia layanan untuk melacak data pasien dari waktu ke waktu, identifikasi pasien untuk kunjungan pencegahan dan skrining, memantau pasien, dan meningkatkan kualitas perawatan kesehatan. Bukan hanya itu, dari segi biaya RME lebih efisien karena tidak mengeluarkan biaya untuk mencetak status dan tidak membutuhkan ruangan/tempat untuk penyimpanan (Pratamawawi et al., 2019).

Rekam medis merupakan dokumen penting bagi setiap institusi layanan kesehatan yang berupa catatan identitas pasien (Rahmadiliyani \& Faizal, 2018). Dengan kata lain rekam medis merupakan fakta yang berkaitan dengan keadaan pasien, riwayat penyakit dan pengobatan masa lalu serta saat ini ditulis oleh profesi sekedar catatan biasa, melainkan ia memuat segala informasi menyangkut seorang pasien yang akan dijadikan dasar untuk menentukan tindakan lebih lanjut kepadanya (Hatta et al., 2008).

Sumber Daya Manusia Kesehatan merupakan seseorang yang bekerja secara aktif di bidang kesehatan, baik yang memiliki pendidikan formal kesehatan maupun tidak yang untuk jenis tertentu memerlukan kewenangan dalam melakukan upaya kesehatan (KemenKes, 2016).

SDM terdiri dari daya pikir dan daya fisik setiap manusia. SDM menjadi unsur pertama dan utama dalam setiap aktivitas yang dilakukan (Larasati, 2018). Peralatan yang handal/canggih tanpa peran aktif SDM bukan berarti apa-apa. Perencanaan Kebutuhan SDMK bertujuan untuk menghasilkan rencana kebutuhan SDMK yang tepat meliputi jenis, jumlah, dan kualifiasi sesuai kebutuhan organisasi berdasarkan metode perencanaan yang sesuai dalam rangka mencapai tujuan pembangunan kesehatan (Fidianti, 2011). Salah satu metode perencanaan kebutuhan tenaga kerja yaitu Analisis Beban Kerja Kesehatan (ABK Kes). Berdasarkan studi pendahuluan yang dilakukan pada tanggal 07 Juli 2021 di unit case mix Rumah Sakit X Palembang dan hasil wawancara dengan staff case mix, rumah Sakit tersebut merupakan rumah sakit dengan jumlah 4 (empat) PMIK coder.

Penyelenggaran rekam medis yang bermutu diperlukan tenaga kesehatan yang bermutudansesuai dengan kompetensinya. tenaga kerja yang baik akan sangat mempengaruhi mutu pelayanan di unit kerja rekam medis (Afnawati et al., 2018). Mutu pelayanan berkaitan dengan beban kerja, 
maka beban kerja harus sesuai dengan jumlah tenaga agar pelayanan menjadi bermutu. Beban kerja adalah besaran pekerjaan yang harus dipikul oleh suatu jabatan atau unit organisasi dan merupakan hasil kali antara volume kerja dan norma waktu (Talib, 2018).

\section{Metode Penelitian}

Jenis penelitian yang digunakan dalam penelitian ini adalah penelitian deskriptif kualitatif (Sugiyono, 2012).

Penelitian ini merupakan penelitian deskriptif dengan pendekatan kualitatif. Menurut (Sugiyono, 2012) metode deskriptif kualitatif adalah metode penelitian yang berdasarkan pada filsafat postpositivisme digunakan untuk meneliti pada kondisi objek yang alamiah (sebagai lawannya adalah eksperimen) dimana peneliti adalah sebagai instrument kunci teknik pengumpulan data dilakukan secara trigulasi (gabungan), analisis data bersifat induktif/kualitatif, dan hasil penelitian kualitatif lebih menekankan makna daripada generalisasi. Penelitian deskriptif kualitatif bertujuan untuk menggambarkan, melukiskan, menerangkan, menjelaskan dan menjawab secara lebih rinci permasalahan yang akan diteliti dengan mempelajari semaksimal mungkin seorang individu, suatu kelompok atau suatu kejadian. Dalam penelitian kualitatif manusia merupakan instrumen penelitian dan hasil penulisannya berupakata-kata atau pernyataan yang sesuai dengan keadaan sebenarnya (Osman et al., 2015).
Subjek penelitian adalah sumber utama penelitian, yaitu yang memiliki data mengenai variabel-variabel yang diteliti (Moleong, 2019). Subjek penelitian ini yaitu semua PMIK coding yang berjumlah 4 (empat) PMIK. Subjek dalam penelitian digunakan sebagai data primer. Informasi atau responden penelitian ini adalah PMIK coding di Rumah Sakit X Palembang.

Teknik analisis data yaitu dengan berpedoman pada jumlah berkas, dan tenaga kerja yang ada saat ini. Instrument penelitian yang digunakan dalam penulisan jurnal ini adalah:

1. Pedoman wawancara kepada staff coding mengenai jumlah berkas pasien rawat inap dan rawat jalan.

2. Variabel penelitian

\section{Hasil dan Pembahasan}

\section{A. Hasil Penelitian}

Perhitungan kebutuhan petugas coding di Rumah Sakit X Palembang dapat dihitung sebagai berikut:

a. Menetapkan fasyankes dan Jenis SDMK Berdasarkan hasil observasi menetapkan fasyankes dan jenis SDMK unit: coding

b. Menetapkan waktu kerja tersedia (WKT)

Waktu kerja tersedia (WKT) adalah waktu yang dipergunakan oleh SDMK untuk melaksanakan tugasdan kegiatannya dalam kurun waktu 1 (satu) tahun.

Tabel 1

Menetapkan Waktu Kerja Tersedia (WKT)

\begin{tabular}{|c|c|c|c|}
\hline Kode & Komponen & Jumlah & Satuan \\
\hline $\mathbf{A}$ & Hari Kerja & 52 minggu $\times 6$ hari $=312$ & Hari/Tahun \\
\hline B & Cuti Pegawai & 12 hari & Hari/Tahun \\
\hline $\mathbf{C}$ & Libur Nasional & 18 hari & Hari/Tahun \\
\hline $\mathbf{D}$ & Mengikuti Pelatihan & 1 & Hari/Tahun \\
\hline $\mathbf{E}$ & Absen (Sakit dll) & 5 hari & Hari/Tahun \\
\hline $\mathbf{F}$ & Waktu Kerja (dalam 1 minggu) & 39 & Jam/Minggu \\
\hline $\mathbf{G}$ & Jam Kerja Efektif (JKE) & $75 \% \times 39$ jam $=29,25$ & Jam/Minggu \\
\hline $\mathbf{H}$ & Waktu Kerja (dalam 1 hari) & $29,25: 6=4,875$ & Jam/Hari \\
\hline
\end{tabular}


Analisa Kebutuhan Tenaga Rekam Medis Berdasarkan Beban Kerja dengan Metode Abk-Kes di Bagian Case Mix Rumah Sakit X Palembang Tahun 2021

\begin{tabular}{cccc}
\hline $\mathbf{I}$ & Waktu Kerja Tersedia (hari) & $312-(12+18+5)$ & Hari/Tahun \\
& & $312-35=277$ & \\
\hline $\mathbf{J}$ & Waktu Kerja Tersedia (jam) & $312-(12+18+5) \mathrm{x}$ & Jam/Tahun \\
& $4,875=$ & \\
& $(312-35) \times 4,875$ & \\
& $=277 \times 4,875$ & \\
& $=1.350$ & \\
& $=1.200$ & Jam/Tahun \\
& $=72.000$ & Menit/Tahun \\
\hline
\end{tabular}

c. Menetapkan komponen beban kerja dan norma waktu berdasarkan observasi menetapkan komponen beban kerja adalah uraian tugas yang dilakukan oleh PMIK coding sesuai tugas pokoknya.

\begin{tabular}{ccc}
\hline No. & Uraian Tugas & Norma Waktu \\
\hline 1. & Koding Rawat Inap & 5 menit \\
\hline 2. & Koding Rawat Jalan & 3 menit \\
\hline & Total & 8 menit \\
\hline
\end{tabular}

d. Menghitung Standar Beban Kerja Standar beban kerja

$$
\frac{72.000}{8}=9.000
$$

Jadi berdasarkan perhitungan dengan metode ABK-Kes jumlah standar beban kerja SIK (Case Mix) yaitu 9.000 menit.

e. Menghitung Standar Tugas Penunjang

Tugas penunjang adalah tugas untuk menyelesaikan kegiatan-kegiatan baik yang terkait langsung atau tidak langsung dengan tugas pokok dan fungsinya yang dilakukan oleh seluruh jenis SDMK.

$$
\begin{aligned}
\text { FTP } & =8: 72.000 \times 100 \% \\
& =0,1 \% \\
\text { STP } & =(1 /(1-0,1 \% / 100)) \\
& =1
\end{aligned}
$$

Berdasarkan hasil perhitungan standar tugas penunjang hasil yang didapat adalah 1 (satu).

Langkah selanjutnya menghitung kebutuhan SDMK.

\begin{tabular}{|ll|}
\hline \multirow{2}{*}{ Kebutuhan } & \multicolumn{2}{c|}{ Capaian (1 th) } \\
\cline { 2 - 2 } & Standar Beban \\
\hline Kebutuhan & sumber daya manusia
\end{tabular}

kesehatan di bagian coder

$$
\begin{array}{ll}
\text { SBK } & =9.000 \\
\text { STP } & =1 \\
\text { SDMK } & =37.440 / 9.000 \times 1 \\
& =4 \text { PMIK coding. }
\end{array}
$$

\section{B. Pembahasan}

Perhitungan kebutuhan PMIK Coding di Rumah Sakit X Palembang.

a. Menghitung waktu kerja tersedia pada Unit Coding Instalasi Case Mix Rumah Sakit X Palembang Tahun 2021.

Waktu Kerja Tersedia (WKT) adalah waktu yang dipergunakan oleh SDMK untuk melaksanakan tugas dan kegiatannya dalam kurun waktu 1 (satu) tahun.

Berdasarkan hasil observasi di Rumah Sakit X Palembang dalam satu minggu melaksanakan 6 hari kerja. Jam kerja karyawan dimulai senin s.d. sabtu pukul 07.30 wib - 14.00 wib.

b. Menghitung Standar Beban Kerja (SBK)

Menurut Permenkes 33 tahun 2015 standar beban kerja (SBK) adalah volume/kuantitas pekerjaan selama 1 tahun untuk tiap jenis SDMK. SBK untuk suatu kegiatan pokok disusun berdasarkan waktu yang dibutuhkan untuk menyelesaiakan setiap kegiatan (rata-rata waktu atau norma waktu) dan 
waktu kerja tersedia (WKT) yang sudah ditetapkan.

Dari perhitungan waktu kerja tersedia, standar beban kerja SIK (Case Mix) di Rumah Sakit X Palembang yaitu 9.000 .

c. Menghitung Standar Tugas Penunjang (STP) dan Faktor Tugas Penunjang (FTP)

Dari perhitungan di Rumah Sakit $\mathrm{X}$ Palembang hasil dari FTP sebesar $0,1 \%$ dan STP sebesar 1 yang nantinya dapat digunakan untuk menghitung jumlah kebutuhan SDMK pada langkah terakhir.

d. Menghitung Kebutuhan SDMK

Menurut Permenkes No. 33 Tahun 2015 tentang pedoman penyusunan perencanaan kebutuhan sumber daya manusia kesehatan, Kebutuhan SDMK dihitung dari capaian 1 tahun yaitu data capaian tugas pokok selama kurun waktu satu tahun dibagi dengan Standar Beban Kerja (SBK) dan dikalikan STP (Standar Tugas Penunjang).

Total SDMK unit coding di Rumah Sakit $X$ Palembang yang didapatkan dari hasil perhitungan langkah ke-enam dibulatkan dan menjadi 4 (empat) PMIK.

\section{Kesimpulan}

Jumlah PMIK coder di Rumah Sakit X Palembang terdapat 4 (empat) PMIK coder. Perhitungan kebutuhan SDMK di bagian SIK (Case Mix) menggunakan metode Analisis Beban Kerja Kesehatan (ABK-Kes) sebanyak 4 (empat) PMIK dan di Rumah Sakit X Palembang terdapat 4 (empat) PMIK sehingga jumlah petugas tersebut masih relatif aman untuk menyelesaikan tugas sesuai beban kerja yang ada.

\section{BIBLIOGRAFI}

Afnawati, A. D., Inayati, A., \& Pratama, T. W. Y. (2018). Ketersediaan Sumber Daya Manusia Dan Pelaksanaan Job Description Dalam Unit Kerja Rekam Medis Rumah Sakit Umum Daerah Sumberrejo. Jurnal Hospital Science, 2(2), 16-21. Google Scholar

Azzahra, S. A. N., \& Mufidi, M. F. (2021). Tanggung Jawab Petugas Kesehatan Terhadap Kerahasiaan Dokumen Pasien Dalam Melakukan Pelayanan Medis Ditinjau Dari Uu No. 44 Thn 2009. Dihubungkan Dengan Permenkes No. 269/Menkes/Per/Iii/2008 Tentang Rekam Medis. Google Scholar

Fidianti, N. (2011). Analisis Kinerja Dinas Kesehatan Kota Pekanbaru (Studi Kasus Penanggulangan Demam Berdarah Dengue Tahun 2011). Google Scholar

Gunawan, T. S., \& Christianto, G. M. (2020). Rekam Medis/Kesehatan Elektronik (Rmke): Integrasi Sistem Kesehatan. Jurnal Etika Kedokteran Indonesia, 4(1), 27-31. Google Scholar

Hatta, N., Yamada, M., Hirano, T., Fujimoto, A., \& Morita, R. (2008). Extramammary Paget's Disease: Treatment, Prognostic Factors And Outcome In 76 Patients. British Journal Of Dermatology, 158(2), 313-318. Google Scholar

Kemenkes, R. I. (2016). Buku Kesehatan Ibu Dan Anak. In Kementrian Kesehat Ri Dan Jica Jakarta. Google Scholar

Larasati, S. (2018). Manajemen Sumber Daya Manusia. Deepublish. Google Scholar

Moleong, L. J. (2019). Metodologi Penelitian Kualitatif. Google Scholar

Osman, S. Z. M., Jamaludin, R., \& Iranmanesh, M. (2015). Student Centered Learning At Usm: What Lecturer And Students Think Of This New Approach?. Journal Of Education 
Analisa Kebutuhan Tenaga Rekam Medis Berdasarkan Beban Kerja dengan Metode Abk-Kes di Bagian Case Mix Rumah Sakit X Palembang Tahun 2021

And Practice, 6(19), 264-277. Google Scholar

Pratamawawi, D. N. P., Hidayat, L. H., Hartami, E., Septina, F., \& Swastirani, A. (2019). Dasar-Dasar Keselamatan Pasien Pada Praktik Dokter Gigi. Universitas Brawijaya Press. Google Scholar

Rahmadiliyani, N., \& Faizal, F. (2018). Kerahasiaan Rekam Medis Di Rumah Sakit Aveciena Medika Martapura. Jurnal Manajemen Informasi Kesehatan Indonesia (Jmiki), 6(2), 69-78. Google
Scholar

Sugiyono, P. D. (2012). Metode Penelitian Kuantitatif Kualitatif Dan R\&D (Vol. 8). Alfabeta. Bandung. Google Scholar

Talib, T. (2018). Analisis Beban Kerja Tenaga Filing Rekam Medis (Studi Kasus Rumah Sakit Ibu Dan Anak Bahagia Makassar). Jurnal Manajemen Informasi Kesehatan Indonesia (Jmiki), 6(2), 123-128. Google Scholar

\section{Copyright holder:}

Hadi Priatmoko, Yuyun Yunengsih, Sali Setiatin (2021)

First publication right:

Jurnal Health Sains

This article is licensed under:

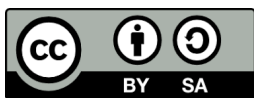

